\title{
DESIGN AND FEM ANALYSIS OF TWO-WHEELER EXHAUST SYSTEM
}

\section{VIVEK YADAV $^{1} \&$ PANKAJ KUMAR ${ }^{2}$}

${ }^{1}$ Student, Department of Mechanical Engineering, Arya Institute of Engineering and Technology, Rajasthan, India

${ }^{2}$ Assistant Professor, Department of Mechanical Engineering, Arya Institute of Engineering and Technology, Rajasthan, India

\begin{abstract}
The exhaust system has to perform many functions like creating pressure difference, controlling vibration and controlling noise. The flue gases releases at very high temperature and high pressure pulses creates a high vibrations. So, it is very necessary to control the vibrations and noise for the comfort of operator and to increase the life of engine. There are various components inside the exhaust system are muffler, silencer, baffle assembly etc. The exhaust system has suffered different types of loading like pressure load, acceleration load, fatigue loading and loading due to selfweight. So in this journal paper, we study the behaviour of silencer and exhaust system on different loading. The model is made on solid works with close dimensions, and analysis is done on Ansys workbench 15.0 software. KEYWORDS:
\end{abstract}

Received: Apr 01, 2020; Accepted: Apr 21, 2020; Published: May 12, 2020; Paper Id.: IJAuERDJUN20203

\section{INTRODUCTION}

The function of silencer is to reduce noise, vibration and pollution. This can be done by two ways one is catalytic convertor and other is silencer. For the working of catalytic convertor the temperature must be approx. $900 \mathrm{oC}$ and this temperature cannot be reached in two wheeler so catalytic convertor cannot be used in two wheeler exhaust system. The other is silencer, which works on the reflection phenomena, it transmits the sound waves towards the end of chamber and chamber reflects back towards the source, these reflect each other and cancel each other. It helps in the reduction of sound.

There is opening and closing of the exhaust valve with each cycle of combustion and the pressure varies from high to low or from low to high, hence silencer has to bear all the vibration. The vibrations vary with the load and the speed, at high load and speed the vibrations are high and thermal stresses are high.

The silencer has thermal stresses so to increase the life of silencer the thermal stress need to be focused and uniform distribution of thermal stresses must be there. The length of the exhaust pipe also affects the efficiency of the engine. If the exhaust gases have to travel a large distance the efficiency decreases as in sports bike it is easily seen that the exhaust pipe is small in length. The Objectives of this paper are

- $\quad$-Cad modelling of existing silencer.

- $\quad$-Cad modelling of internal parts of silencer.

- -Analysis of internal parts of silencer.

- -Analysis of full exhaust system.

\section{Analysis of Silencer}


Silencer is mainly pressure reducing instrument, but back pressure effects a lot generally more the back pressure less is the efficiency, back press is the pressure which restricts the flow of exhaust gases from combustion chamber mainly better the muffler in restricting sound more back pressure is created. So, there should be optimization between the two noises and back pressure.

\section{Size}

The available space has also an influence on the size and the type of muffler that may be used. A muffler is mainly designed for optimum attenuation however if it takes large space then, it is useless. Largermuffler is high in weight, and leads to high manufacturing cost. For a high performance vehicle it affects performance/acceleration, etc. Therefore, a small light weight muffler is desirable.

\section{Transmission Loss}

Transmission loss is the characteristic parameter, which shows the performance of muffler. Transmission loss is varying with respect to change in geometry parameters such as diameter of pipe, number of holes, and number of pipes.

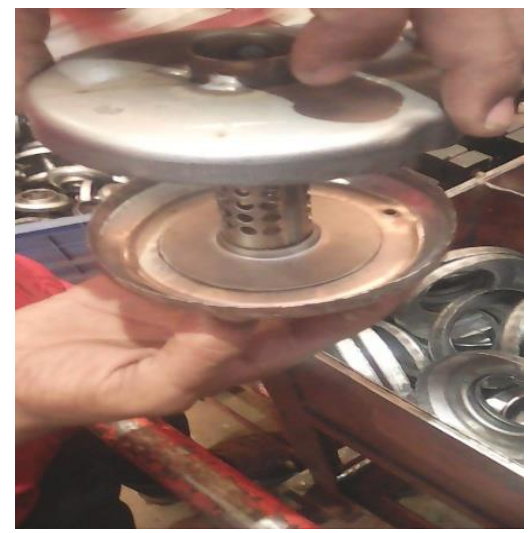

Figure 1: (Silencer Assembly).

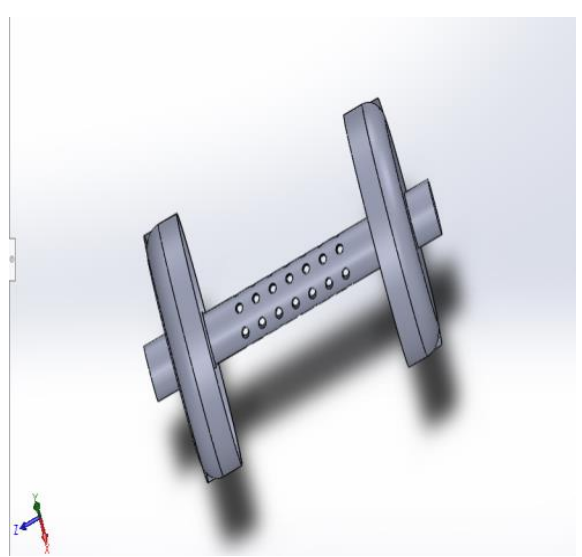

Figure 2: (Model Silencer Assembly).

ANSYS is finite element analysis (FEA) software package. Finite Element Analysis is a numerical method of breaking a complex system into very small pieces (of user defined size) called elements. The software uses equations that govern the elements size and solves them all. These results then can be presented in graphical forms, or tabulated form. This type of analysis is mainly done to complex geometries. The analysis is carried out in ansys fluent the solver is pressure based solver. Energy model is kept on. The flow material is the air. Boundary condition of inlet is pressure type and outlet is the 
pressure outlet type. The proper initialization is fixed and the calculation is made to run. The following results are obtained as below.

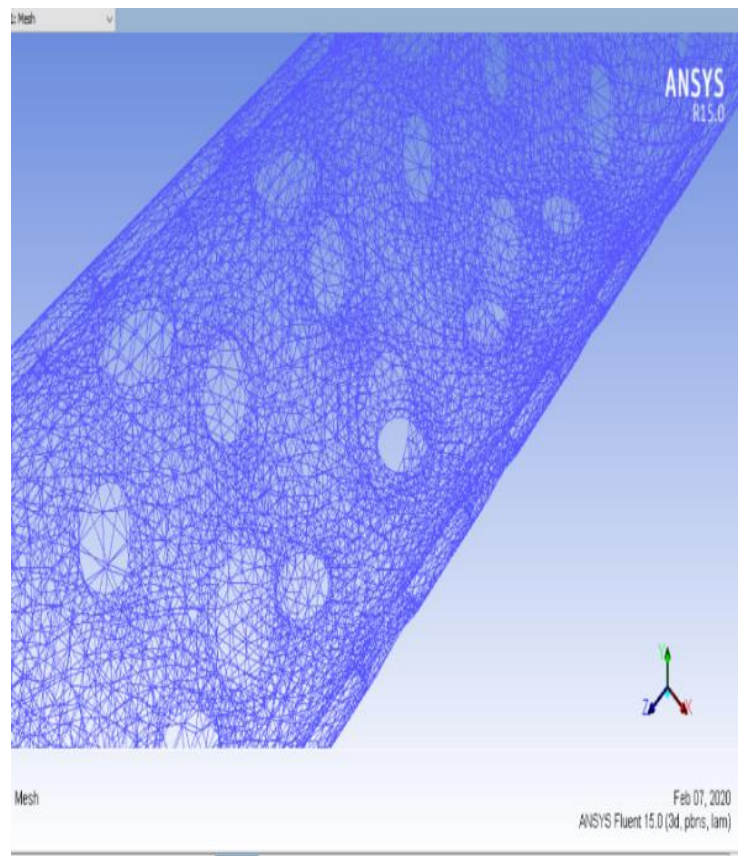

Figure 3: Meshing Pattern.

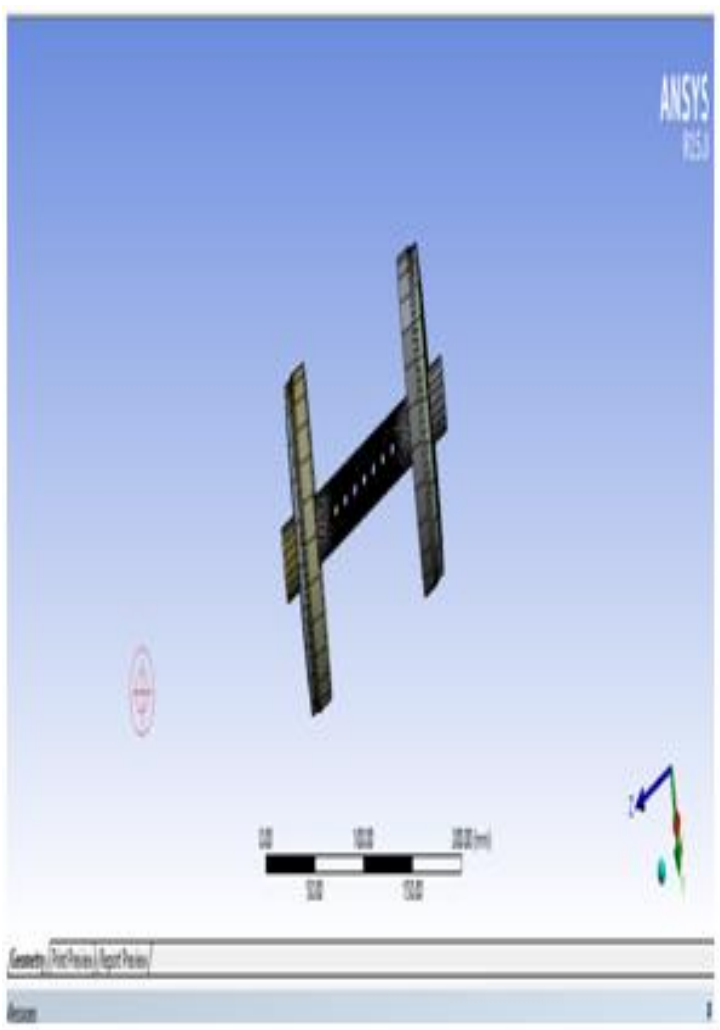

Figure 4: Meshing. 


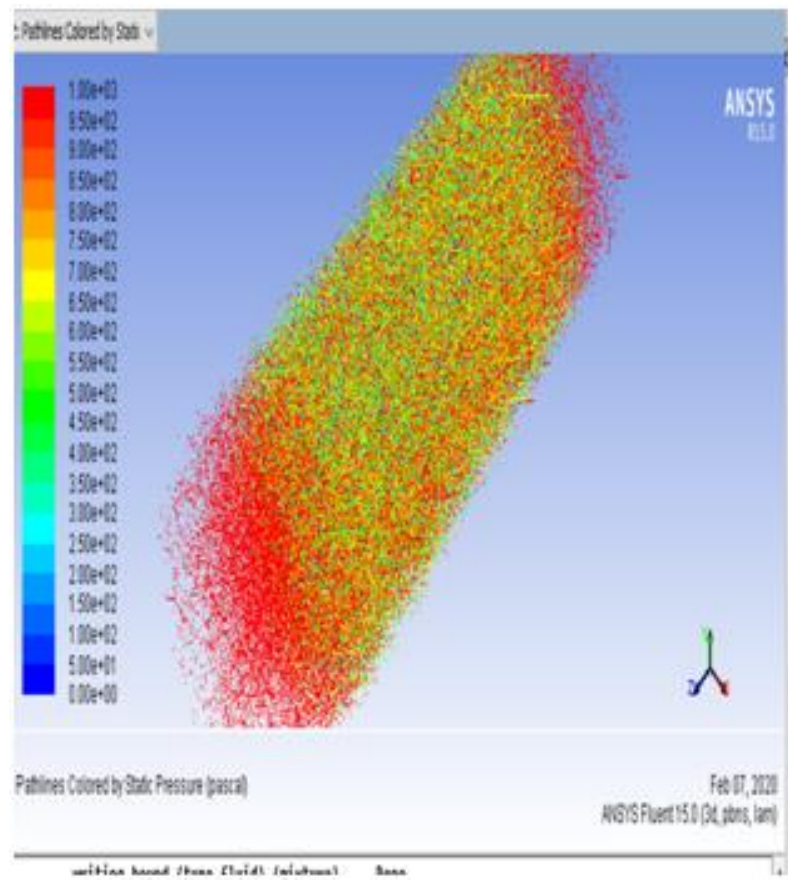

Figure 5: Pressure Distribution in Particles.

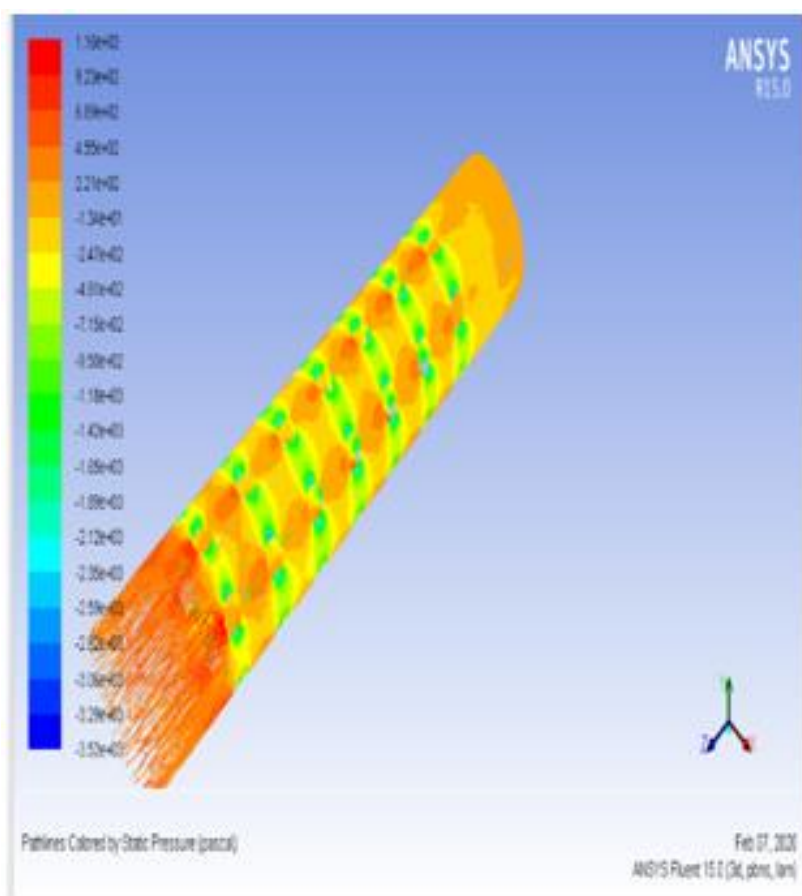

Figure 6: Pressure Distribution in Fluid.

Following changes are being considers 


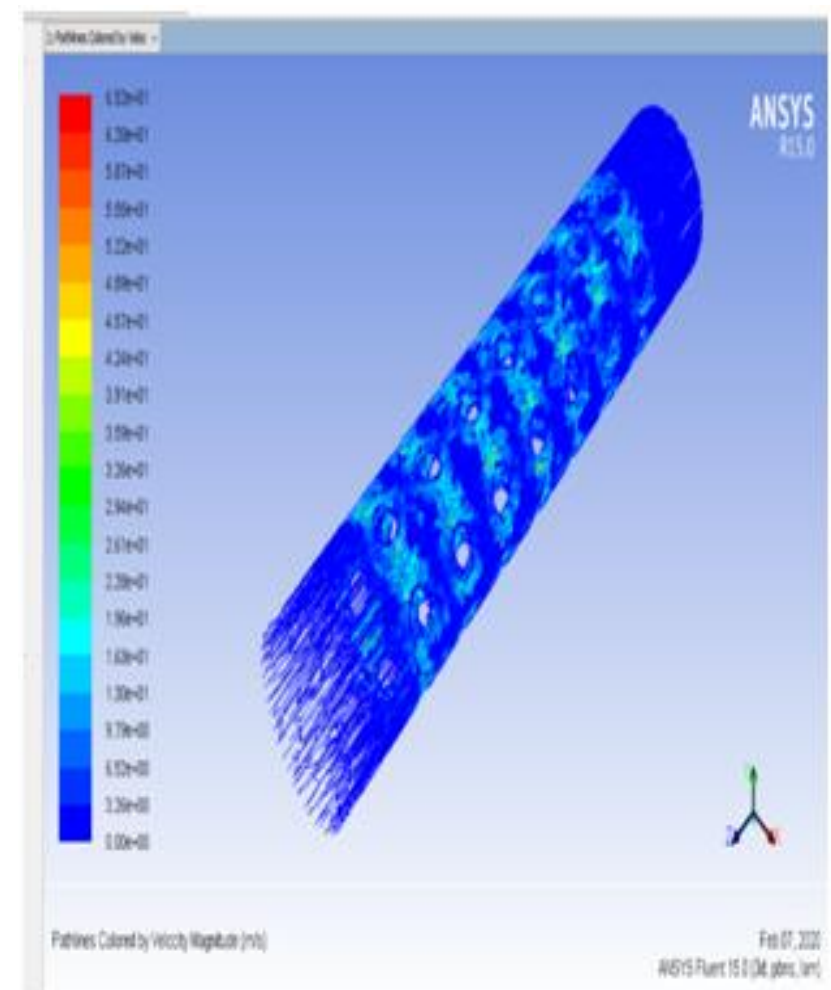

Figure 7: Velocity Distribution in Silencer.

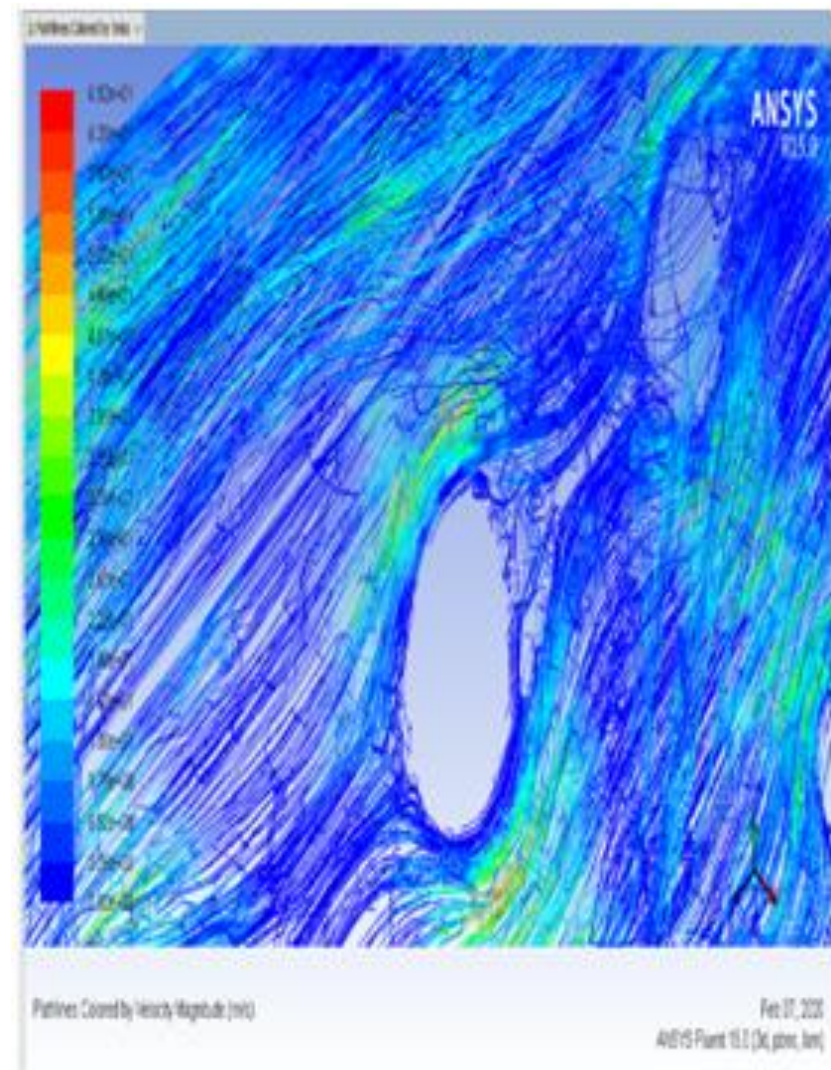

Figure 8: Velocity Distribution Near Holes. 


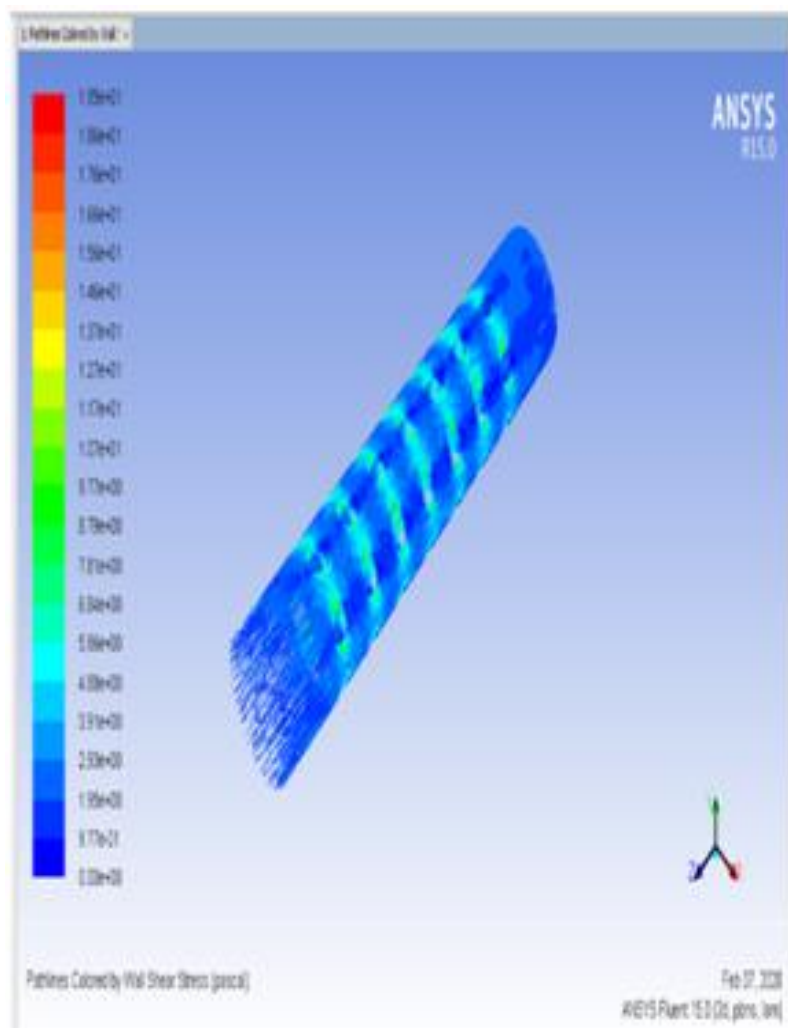

Figure 9: Strain Rate in Silencer.

\section{Analysis of Full Exhaust System}

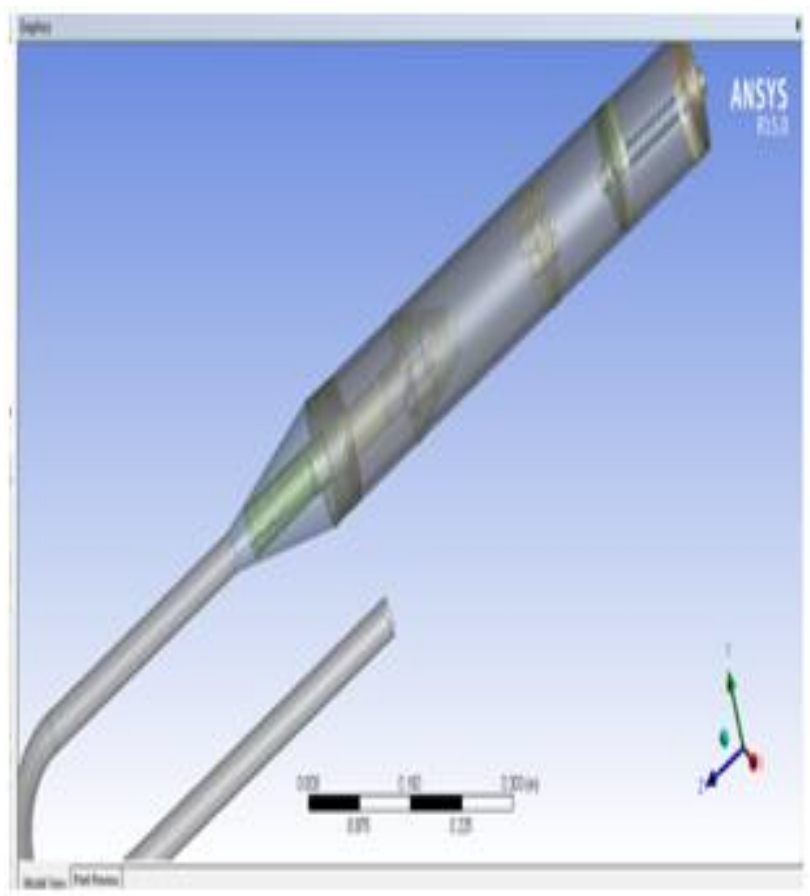

Figure 10: Shear Stress in Silencer. 


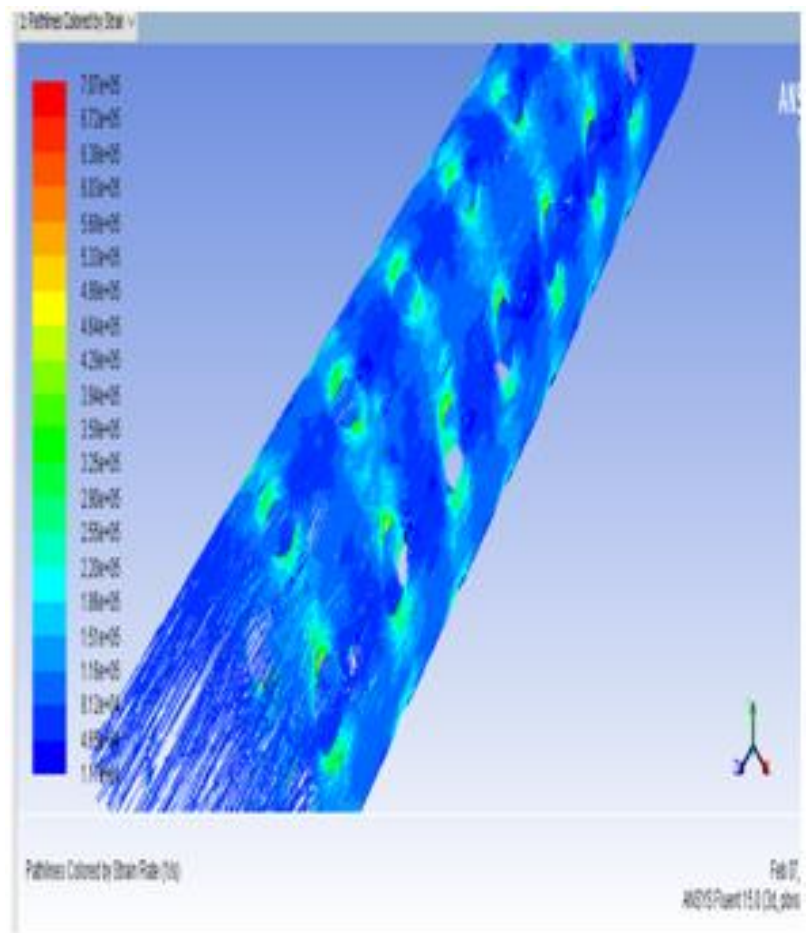

Figure 11: Internal Views of Exhaust System.

Following changes are being considered-

- $\quad$ Number of holes to be modified.

- $\quad$ By changing geometry of the holes such as elliptical, triangular, rectangular etc. have different effect.If we change the baffle location then it results in change in noise pattern.

- By changing geometry of the holes such as elliptical, triangular, rectangular etc. have different effect.

- If we change the baffle location, then it results in change in noise pattern.

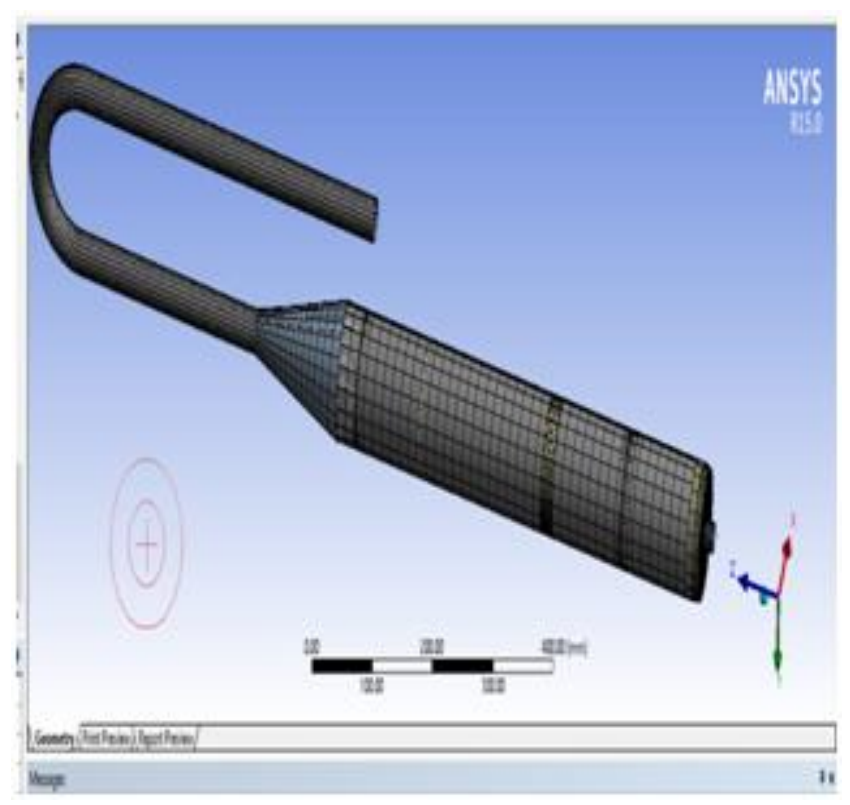

Figure 12: Meshing of Exhaust System. 


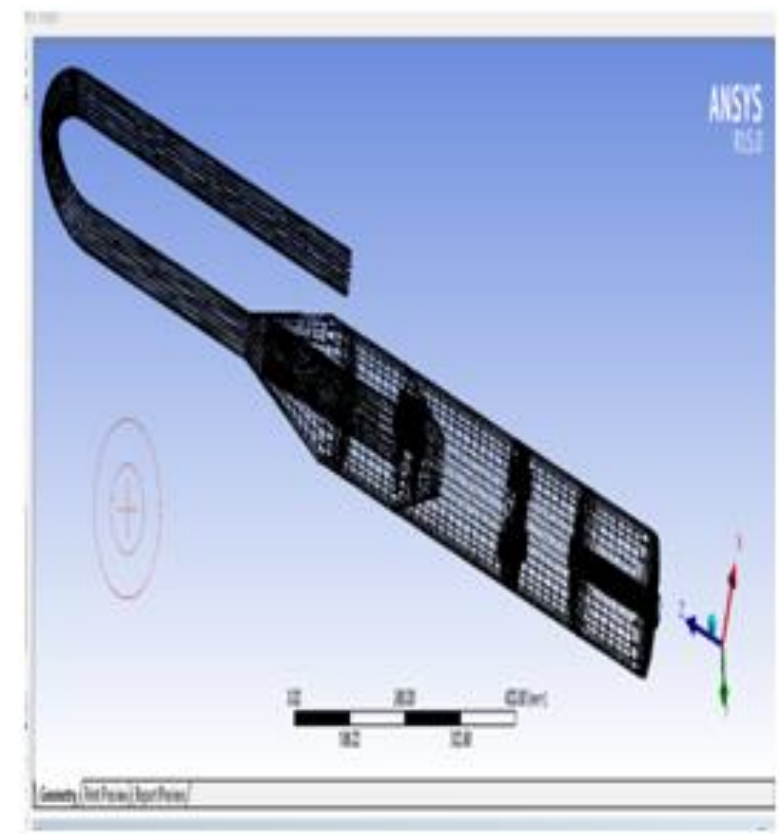

Figure 13: Meshing Internal Parts View.

Table 1

\begin{tabular}{|l|c|}
\hline \multicolumn{2}{|c|}{ Model Meshing Details } \\
\hline Use Advanced Size Function & On: Curvature \\
\hline Relevance Center & Coarse \\
\hline Initial Size Seed & Active Assembly \\
\hline Smoothing & Medium \\
\hline Transition & Fast \\
\hline Span Angle Center & Coarse \\
\hline Curvature Normal Angle & Default $\left(30.0^{\circ}\right)$ \\
\hline Min Size & Default $(1.39070 \mathrm{~mm})$ \\
\hline Max Face Size & Default $(6.95370 \mathrm{~mm})$ \\
\hline Max Size & Default $(6.95370 \mathrm{~mm})$ \\
\hline Growth Rate & Default \\
\hline Minimum Edge Length & $0.561720 \mathrm{~mm}$ \\
\hline Use Automatic Inflation & None \\
\hline Nodes & 95710 \\
\hline Elements & 29812 \\
\hline Mesh Metric & None \\
\hline
\end{tabular}

Structural Steel

Table 2

\begin{tabular}{|l|c|}
\hline \multicolumn{1}{|c|}{ Density } & $\mathbf{7 . 8 5 e - 0 0 6 ~} \mathbf{~ g ~ ~ m m}^{\wedge} \mathbf{- 3}$ \\
\hline Coefficient of Thermal Expansion & $1.2 \mathrm{e}-005 \mathrm{C}^{\wedge}-1$ \\
\hline Specific Heat & $4.34 \mathrm{e}+005 \mathrm{~mJ} \mathrm{~kg}^{\wedge}-1 \mathrm{C}^{\wedge}-1$ \\
\hline Thermal Conductivity & $6.05 \mathrm{e}-002 \mathrm{~W} \mathrm{~mm}{ }^{\wedge}-1 \mathrm{C}^{\wedge}-1$ \\
\hline Resistivity & $1.7 \mathrm{e}-004 \mathrm{ohm} \mathrm{mm}$ \\
\hline
\end{tabular}


Structural Steel > Alternating Stress Mean Stress

Table 3

\begin{tabular}{|c|c|c|}
\hline $\begin{array}{c}\text { Alternating Stress } \\
\mathbf{M P a}\end{array}$ & Cycles & $\begin{array}{c}\text { Mean Stress } \\
\mathbf{M P a}\end{array}$ \\
\hline 3999 & 10 & 0 \\
\hline 2827 & 20 & 0 \\
\hline 1896 & 50 & 0 \\
\hline 1413 & 100 & 0 \\
\hline 1069 & 200 & 0 \\
\hline 441 & 2000 & 0 \\
\hline 262 & 10000 & 0 \\
\hline 214 & 20000 & 0 \\
\hline 138 & $1 . \mathrm{e}+005$ & 0 \\
\hline 114 & $2 . \mathrm{e}+005$ & 0 \\
\hline 86.2 & $1 . \mathrm{e}+006$ & 0 \\
\hline
\end{tabular}

Structural Steel > Strain-Life Parameters

Table 4

\begin{tabular}{|c|c|c|c|c|c|}
\hline $\begin{array}{c}\text { Strength } \\
\text { Coefficient } \\
\text { MPa }\end{array}$ & $\begin{array}{c}\text { Strength } \\
\text { Exponent }\end{array}$ & $\begin{array}{c}\text { Ductility } \\
\text { Coefficient }\end{array}$ & $\begin{array}{c}\text { Ductility } \\
\text { Exponent }\end{array}$ & $\begin{array}{c}\text { Cyclic Strength } \\
\text { Coefficient MPa }\end{array}$ & $\begin{array}{c}\text { Cyclic Strain } \\
\text { Hardening Exponent }\end{array}$ \\
\hline 920 & -0.106 & 0.213 & -0.47 & 1000 & 0.2 \\
\hline
\end{tabular}

Structural Steel > Isotropic Elasticity

Table 5

\begin{tabular}{|c|c|c|c|c|}
\hline Temperature C & Young's Modulus MPa & Poisson's Ratio & Bulk Modulus MPa & Shear Modulus MPa \\
\hline & $2 . e+005$ & 0.3 & $1.6667 \mathrm{e}+005$ & 76923 \\
\hline
\end{tabular}

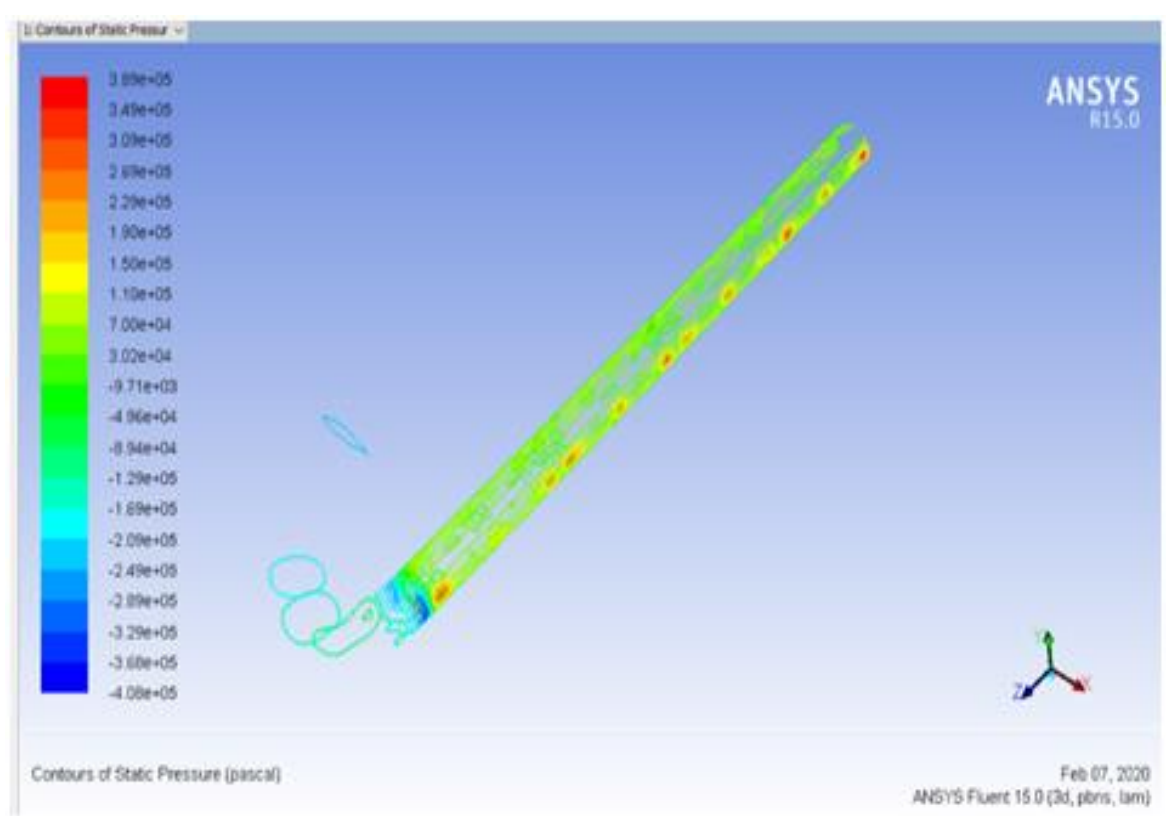

Figure 14: Pressure Distribution Pulses from Exhaust Valve. 


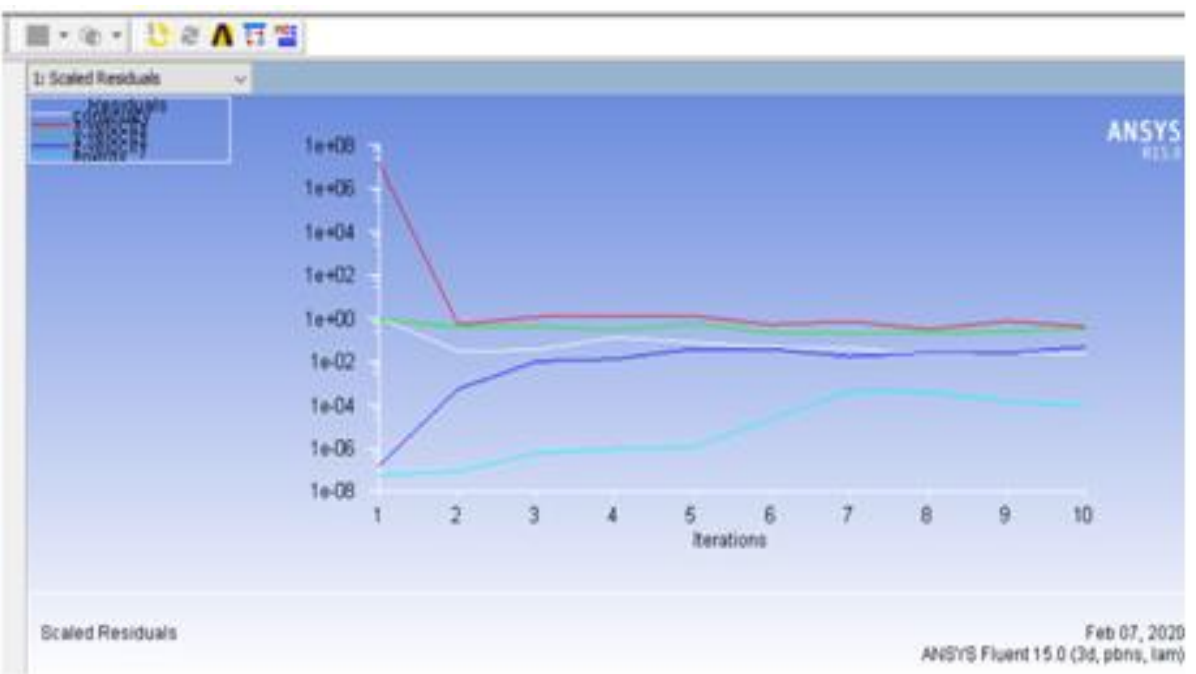

Figure 15: Iteration Diagram.

Computational fluid dynamics (CFD) is the branch of fluid mechanics that uses numerical Analysis to analyse the behaviour of fluid flows. In this, the computer is used for analysis which includes graphical representation and numerical result with the entire boundary conditioned. Presently, result is analysed in FLUIDFLOW fluentmodule, the pressure distribution, velocity distribution, shear stress distribution, strain rate and frequency distribution is obtained on the modal analysis, all are analysed in ANSYS WORKBENCH 15.0.

\section{Frequency Distribution and Displacement}

Every object has an internal frequency, at which, the object can vibrate naturally. It is that frequency too, with which it transfer its energy from one form to another like vibration energy to heat energy or kinetic energy. As the frequency increase, the amplitude increases to infinity. And same here, the result of model analysis is finding the frequency, where the amplitude increases to infinity. When the time varying load is applied, it similarly acts as the vibrational forces and when these forces transmitted to the system, it acts in some displacement, and due to friction it also generates some heat.

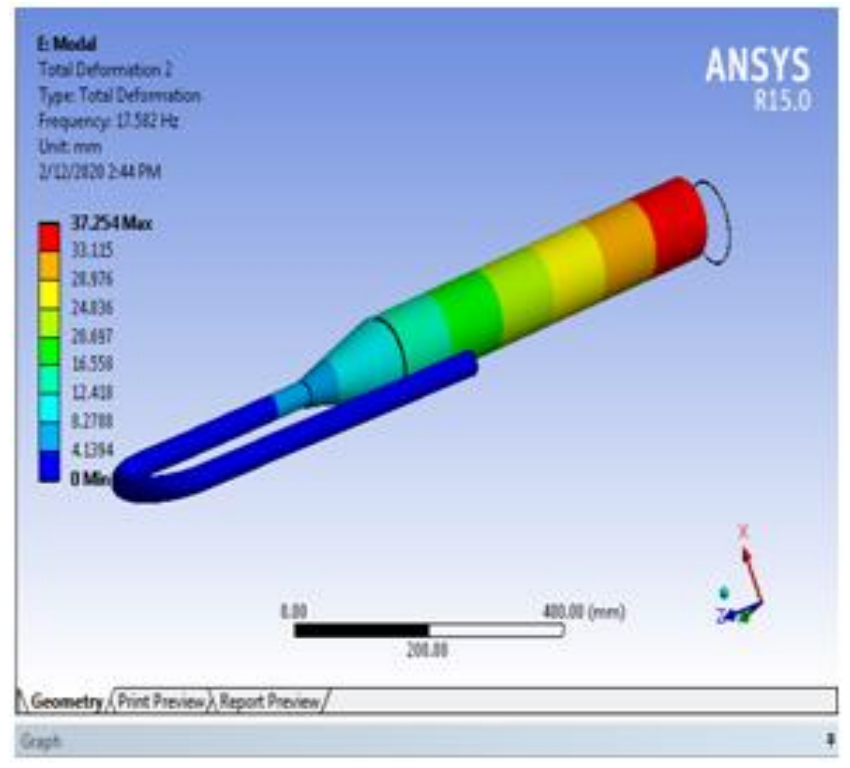

Figure 16: Deformation 2. 


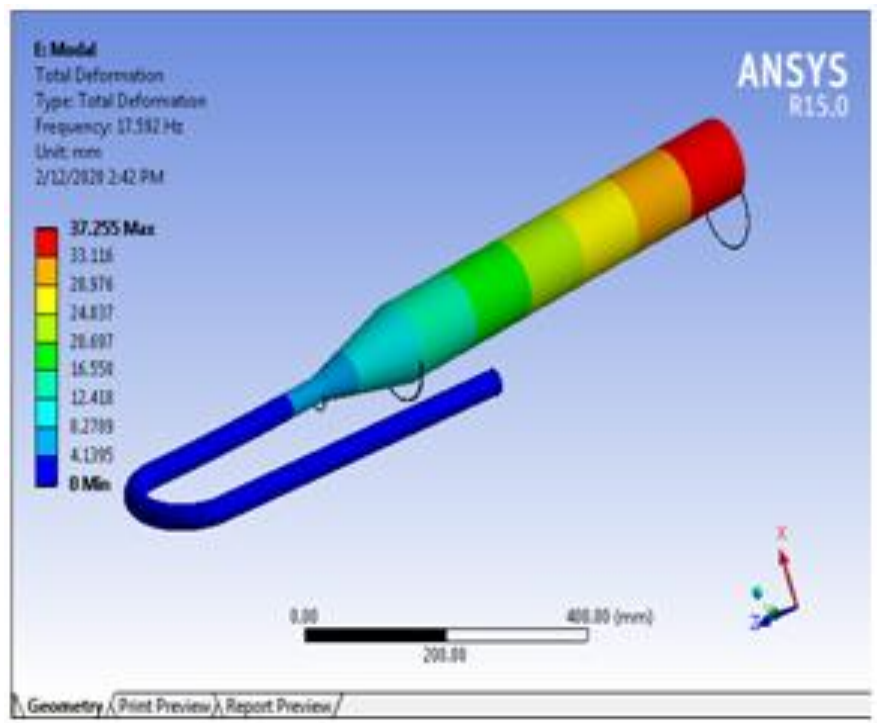

Figure 17: Deformation 1.

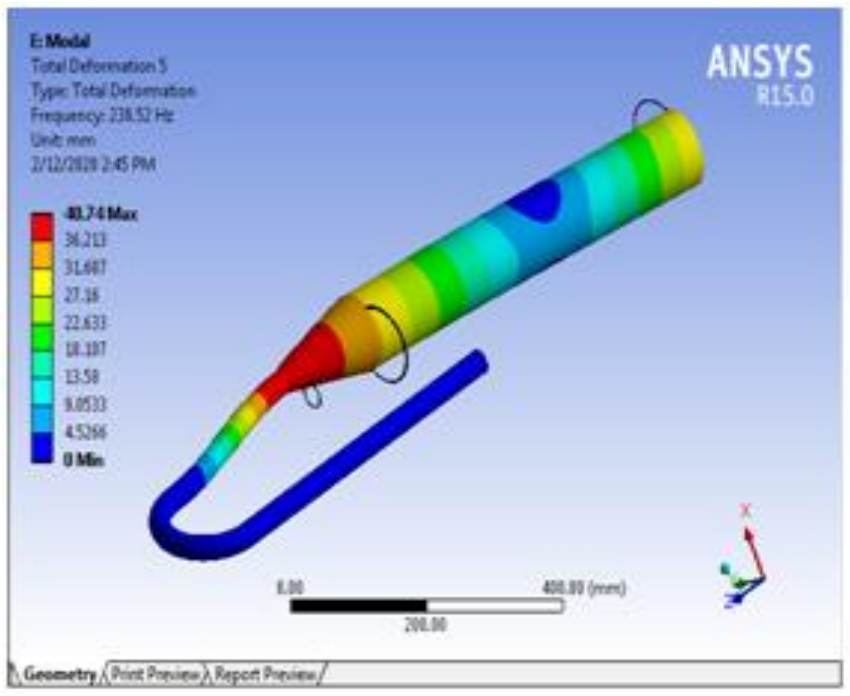

Figure 18: Deformation 5.

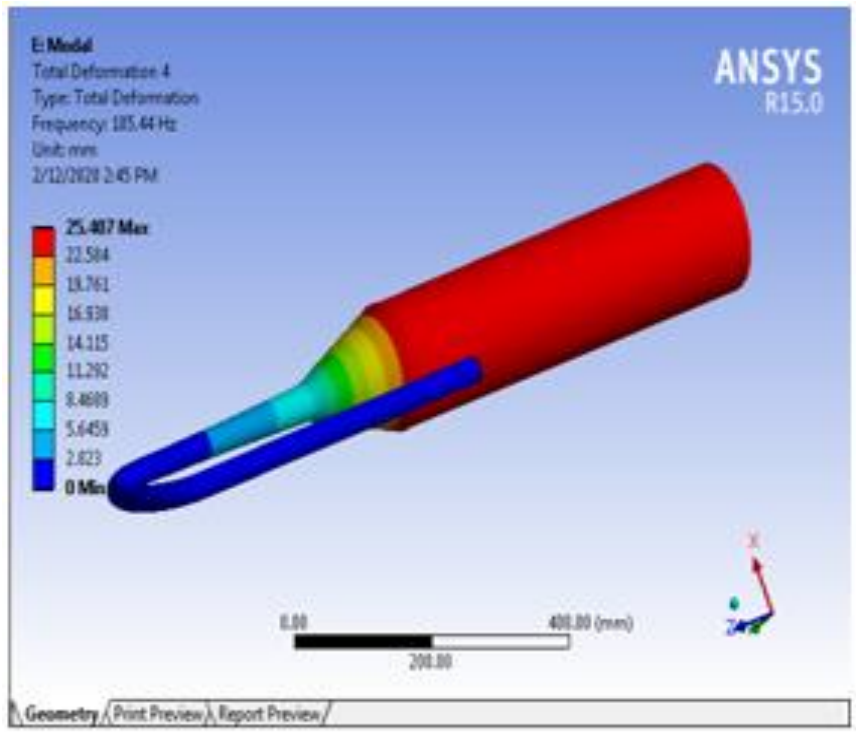

Figure 19: Deformation 4. 


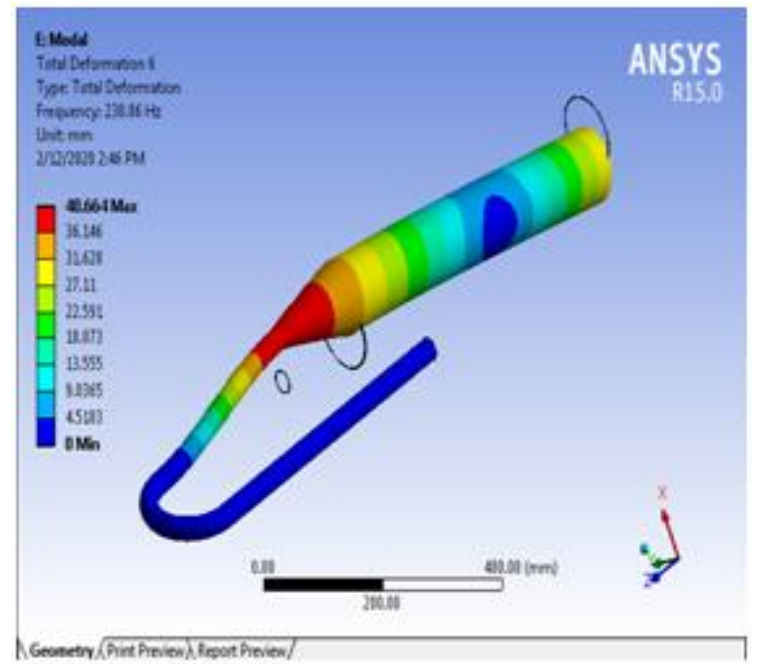

Figure 20: Deformation 6.

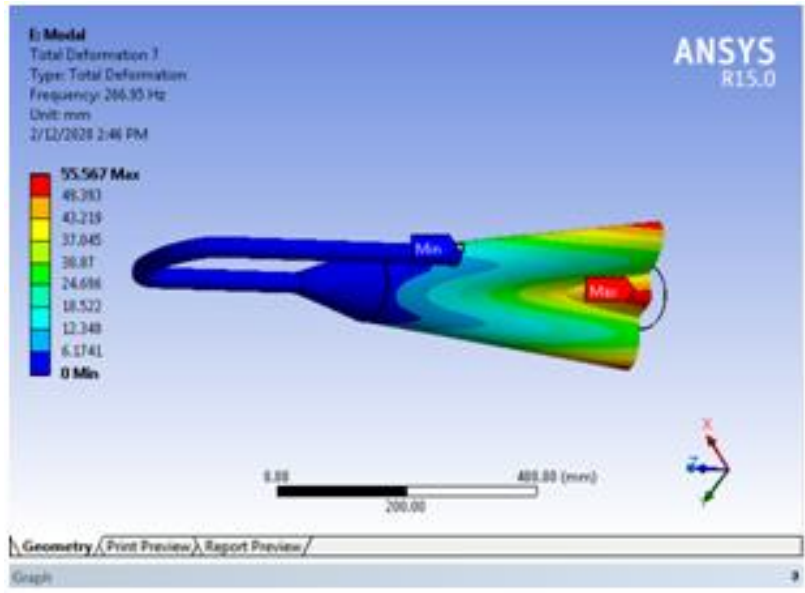

Figure 21: Deformation 7.

\section{RESULT AND DISCUSSIONS}

Table 6

\begin{tabular}{|l|c|c|c|c|c|c|c|}
\hline \multicolumn{1}{|c|}{ Mode } & $\mathbf{1}$ & $\mathbf{2}$ & $\mathbf{3}$ & $\mathbf{4}$ & $\mathbf{5}$ & $\mathbf{6}$ & $\mathbf{7}$ \\
\hline Frequency & 17.592 & 17.582 & 18.599 & 185.44 & 238.52 & 238.86 & 266.95 \\
\hline Min.Displacement & 0 & 0 & 0 & 0 & 0 & 0 & 0 \\
\hline Max. Displacement & 37.255 & 37.254 & 37.366 & 25.407 & 40.74 & 40.664 & 55.567 \\
\hline
\end{tabular}

\section{Frequency is in $\mathrm{HZ}$}

\section{Displacement in MM}

As we can see in the above result, the 4 mode has least displacement and mode 7 has the highest displacement. With the increase in the frequency, the displacement must increase but mode 4 determines that value where the engine provides the best performance, and the exhaust system work perfectly according to design criteria. 


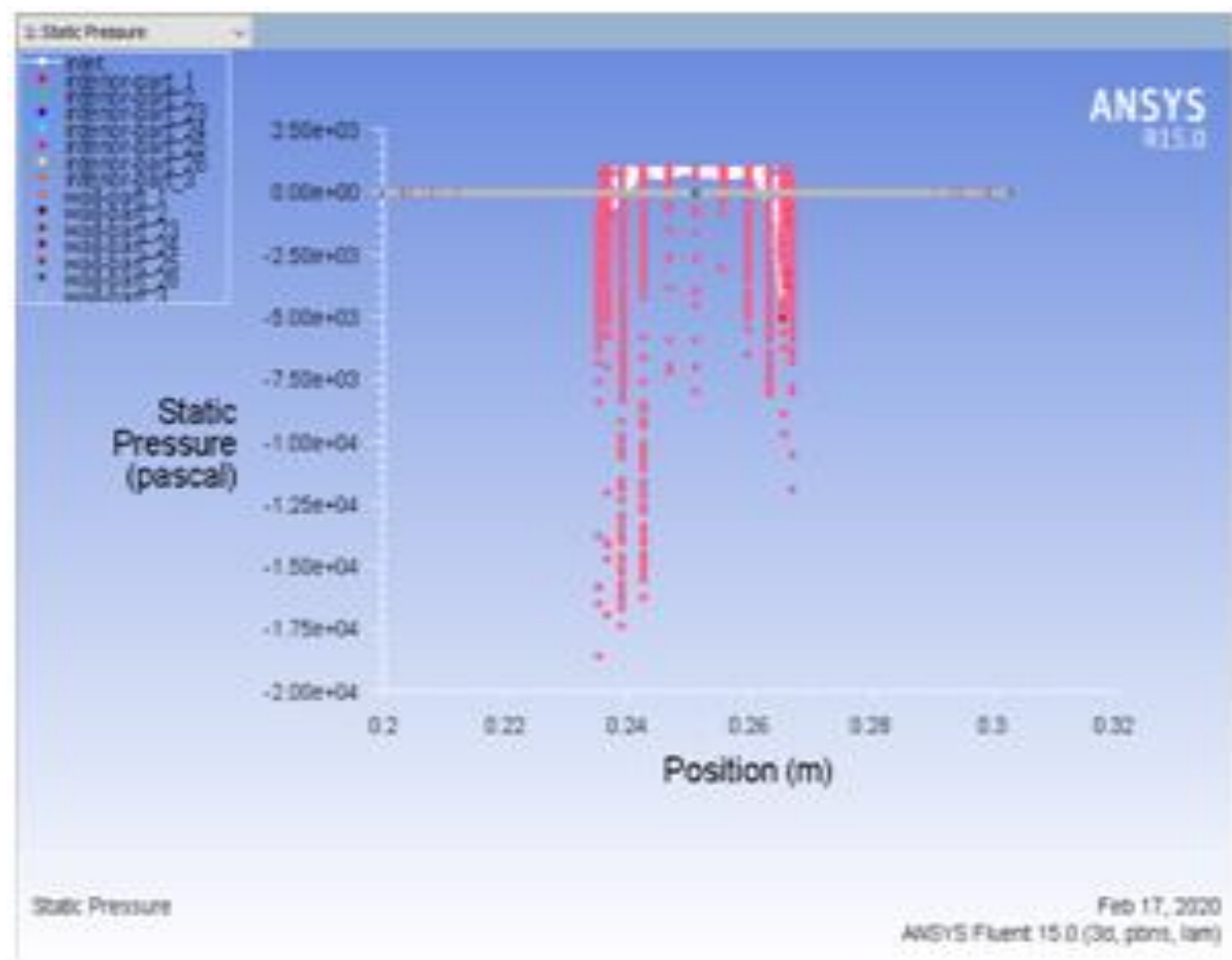

Figure 22: The Pressure Distribution at Different Parts of Exhaust System.

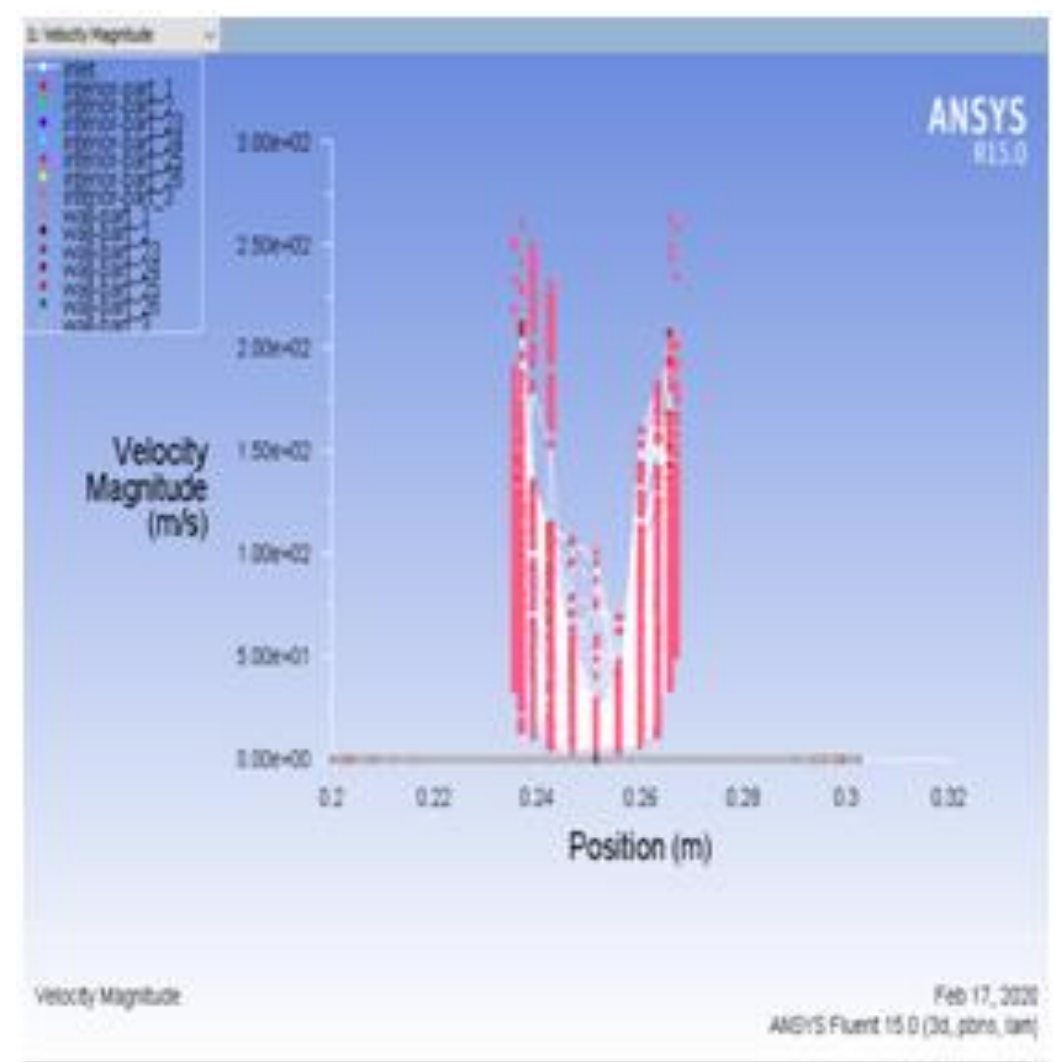

Figure 23: The Velocity Magnitude at Different Parts. 


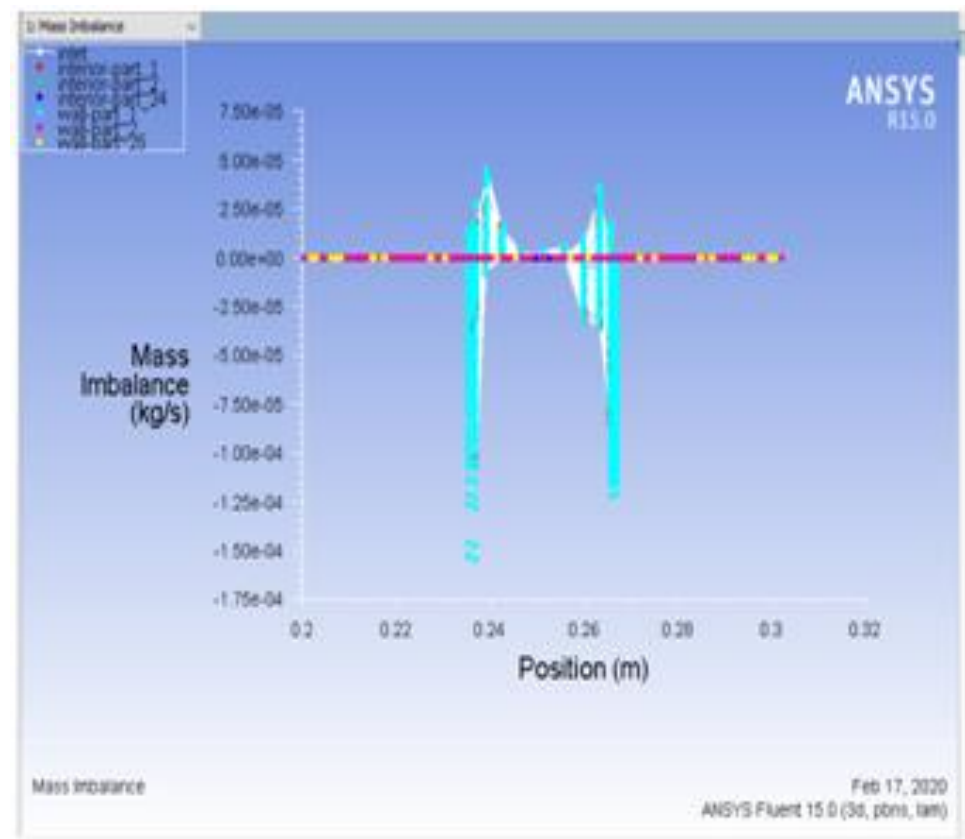

Figure 24: Mass Flow Rate at Different Parts.

\section{CONCLUSIONS}

We conclude that, optimization using FEA is effective than other method, so we go for Optimization of Silencer, the Design Based on Dimensional Parameter.

After the analysis of temperature distribution, the result comes out that the maximum temperature is at the import port edge and the minimum temperature is on the outlet port edge. And, with the increase in the length of the exhaust system, the losses increases but sound level decreases; and with short exhaust system, the losses become less but sound level increases.

\section{REFERENCES}

1. Vijay M Mundhe, Eknath R Deore, "Design and analysis of perforated muffler in Automobile Exhaust System” International journal of multidisciplinary research and development, Volume: 2, Issue: 7, 182-187July 2015.

2. Naikankatte Gowrav, "Thermal analysis of two wheeler exhaust pipe by Finite element method", International Journal of Research, Volume: 05, Issue: 07, March 2018.

3. Alavala, CHENNAKESAVA R. "FEM analysis of single point incremental forming process and validation with grid-based experimental deformation analysis." International Journal of Mechanical Engineering 5.5 (2016): 1-6.

4. A.Ravinthiran, D.K.Jayanth Naidu, S.Hareesh, N.Gurusubramani, K.S.Athvaith Muthukumar, "Investigation of Heat Dissipation between Dimple and Normal Silencer made of Chrome Steel”, International Journal of Recent Technology and Engineering (IJRTE) I, Volume-8 Issue-1S2, May 2019.

5. Krishnaveni, J., G. Sowmya, and U. Sudhakar. "Thermal Analysis Of Cylinder Head By Using Finite Element Analysis." International Journal of Mechanical Engineering (IJME) ISSN (P) (2014): 2319-2240.

6. Saumil Mahesh Trived, Sangita Bansode, Pankaj Pawar, "Structural Analysis and Optimization of ExhaustMuffler", International Journal for Research in Applied Science \& Engineering Technology (IJRASET), Volume-5 Issue- VIII, August 2017. 
7. Gupta, Ishwar, and Gaurav Saxena. "Structural analysis of rotor disc of disc brake of Baja SAE 2013 car through finite element analysis." International Journal of Automobile Engineering Research and Development (IJAuERD) Vol, 4, 1 10 (2014).

8. Jashanpreet Singh, S. P. Nigam, L. K. Bhagi, "A Study on Effectiveness of Muffler on a Two-wheeler vehicle Noise”, International Advanced Research Journal in Science, Engineering and Technology Vol. 4, Special Issue 3, February 2017.

9. Sri, Navya, and A. Chennakesava Reddy. "Formability of Elliptical SS304 Cups in Single Point Incremental Forming Process by Finite Element Method." International Journal of Research in Engineering \& Technology 4.11 (2016): 9-16.

10. Vishal M. Shrivastav, Prof. S. B. Bawaskar, "Design the Exhaust System for the Two Wheeler \& Analysis using FEA", International Journal for Scientific Research \& Development, Vol. 6, Issue 05, 2018.

11. Vinay Gupta, Dhananjay Kr. Singh, Dhirendra kr. Singh, Madan Mohan Mishra, Satish Kumar Dwivedi, Ajay Yadav, “vibrational analysis of exhaust muffler”, International Journal of Scientific \& Engineering Research, Volume 4, Issue 6, June2013.

\section{AUTHORS PROFILE}

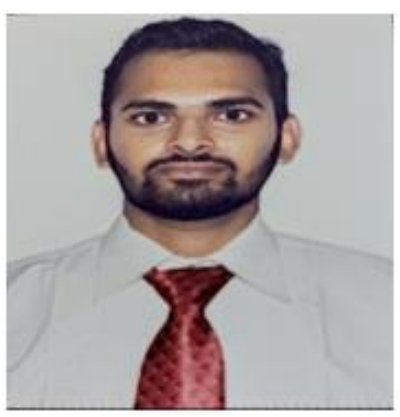

VivekYadav student of Mechanical Engineering.

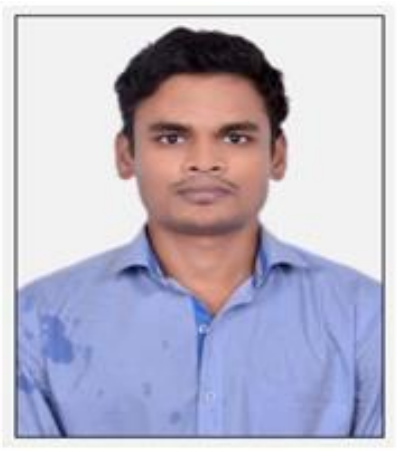

Pankaj Kumar, M.Tech (Manufacturing Technology), National Institute of Technology, Calicut, Kerla 

